\title{
DOSES DE COMPOSTO ORGÂNICO COMERCIAL NA COMPOSIÇÃO DE SUBSTRATOS PARA A PRODUÇÃO DE MUDAS DE MARACUJAZEIRO EM DIFERENTES TIPOS DE CULTIVO PROTEGIDO
}

\author{
EDILSON COSTA ${ }^{1}$, PAULO A. M. LEAL ${ }^{2}$, ADRIANO R. SASSAQUI ${ }^{3}$, \\ VIVIANE DO A. GOMES
}

\begin{abstract}
RESUMO: Doses de composto orgânico comercial misturado ao solo foram utilizadas como substrato na produção de mudas de maracujazeiro amarelo. $\mathrm{O}$ experimento foi conduzido no Campus de Aquidauana, da Universidade Estadual de Mato Grosso do Sul, de setembro a dezembro de 2007. Utilizaram-se seis ambientes protegidos: estufa plástica com pé-direito de 2,5m; viveiro telado com Sombrite ${ }^{\circledR} 50 \%$, com pé-direito de $2,5 \mathrm{~m}$; viveiro telado de tela termo-refletora Aluminet ${ }^{\circledR} 50 \%$, com pé-direito de $2,5 \mathrm{~m}$; viveiro coberto com palha de coqueiro, com pé-direito de $1,8 \mathrm{~m}$; estufa plástica com pé-direito de $4,0 \mathrm{~m}$, possuindo abertura zenital e tela termo-refletora $50 \%$ sob o plástico e, viveiro telado de tela de sombreamento $50 \%$, com pé-direito de $3,5 \mathrm{~m}$. Foram utilizados cinco substratos com doses de $0,7,14,21$ e $28 \%$ de composto orgânico misturado ao solo. Utilizou-se o delineamento em parcelas subdivididas, com dez repetições. As parcelas principais foram os ambientes de cultivo e as subparcelas foram os substratos. Conclui-se que a estufa agrícola com altura de 4,0m, o viveiro agrícola com altura de $3,5 \mathrm{~m}$ e o viveiro coberto com palha de coqueiro nativo propiciaram melhor desenvolvimento das mudas. As doses de 7\%, $14 \%$ e $21 \%$ de composto orgânico se mostraram viáveis para composição de substratos com solo da região.
\end{abstract}

PALAVRAS-CHAVE: Passiflora edulis Sims f. flavicarpa Deg., estufas, viveiros, substratos.

\section{CONTENTS OF COMMERCIAL ORGANIC COMPOUND IN THE PRODUCTION OF PASSIFLORA SEEDLINGS IN DIFFERENT TYPES OF PROTECTED CULTIVATION}

\begin{abstract}
Contents of commercial organic compound mixed with soil were used as substrate in the production of Passiflora edulis Sims f. flavicarpa Deg. seedlings. The experiment was carried out in the Aquidauana Campus at the State University of Mato Grosso do Sul, from September to December of 2007. Six environments were used: plastic greenhouse with height of $2.5 \mathrm{~m}$; nursery with height of $2.5 \mathrm{~m}$ covered by shade net with black monofilament of $50 \%$ shading rate; nursery with height of $2.5 \mathrm{~m}$ covered by Aluminum shading screen with shading rate of $50 \%$; nursery with height of $1.8 \mathrm{~m}$ covered by straw of native coconut; plastic greenhouse with height of $4.0 \mathrm{~m}$, zenith opened and thermal shade netting from Aluminet ${ }^{\circledR}$ under the roof and nursery with height of $3.5 \mathrm{~m}$ covered by shade net with black monofilament of $50 \%$ shading rate. Five commercial organic compound contents of $0,7,14,21$ and $28 \%$, mixed with soil were used. The experiment was carried out in a completely randomized split-plot scheme where the environments were principal plot and substrates were subplots. The greenhouse with height of $4.0 \mathrm{~m}$, the nursery with height of $3.5 \mathrm{~m}$ and the nursery covered with coconut fibers showed the best seedlings. The contents of $7 \%, 14 \%$ and $21 \%$ of commercial organic compounds were viable for composition of the substrates with local soil.
\end{abstract}

KEYWORDS: Passiflora edulis Sims f. flavicarpa Deg., greenhouse, nurseries, substrates.

\footnotetext{
${ }^{1}$ Prof. Dr., Universidade Estadual de Mato Grosso do Sul (UEMS), Unidade Universitária de Aquidauana. Rodovia Aquidauana CERA, km 12, Zona Rural, Aquidauana - MS, mestrine@uems.br.

${ }^{2}$ Prof. Dr., Faculdade de Engenharia Agrícola, Conselho Integrado de Tecnologia de Processos, FEAGRI, Universidade Estadual de Campinas,pamleal@feagri.unicamp.br.

${ }^{3}$ Bolsista PIBIC, UEMS/Aquidauana, adrianosassaqui@ hotmail.com.

${ }^{4}$ Bolsista PIBIC, UEMS/Aquidauana, vivi_maral99@ hotmail.com.

Recebido pelo Conselho Editorial em: 27-3-2009
}

Aprovado pelo Conselho Editorial em: 30-5-2010 


\section{INTRODUÇÃO}

A fruticultura está em plena expansão no Brasil, auxiliando, tanto os pequenos produtores que empregam mão de obra familiar quanto os grandes produtores que utilizam alta tecnologia e contribuem com as exportações no agronegócio nacional. Inserido nesse setor, a produção do maracujazeiro com sua importância comercial, na área alimentícia e medicinal, gera empregos e renda. Dentro da cadeia agroindustrial desse fruto, pesquisas e tecnologias de produção de mudas proporcionam plantas sadias e vigorosas para a formação dos pomares.

Apresentando mais de 150 espécies nativas, o Brasil destaca-se na produção de maracujá, sendo um dos maiores produtores mundiais, onde, no período de 1997 a 2004, a área de produção permaneceu, praticamente, inalterada, em torno de 35 mil hectares (GONÇALVES \& SOUZA, 2006), contudo a produção passou de 357 para 491 mil toneladas (QUINTINO, 2007). Em 2008, atingiu produção de 682 mil toneladas, em área de 49 mil hectares (IBGE, 2008).

Fatores como ambientes de cultivo (MENDONÇA et al., 2005; ZANELLA et al., 2006; KOSOSKI et al., 2008), substratos (SILVA et al., 2001; SILVEIRA et al., 2003; ALMEIDA, 2003; PIO et al., 2004, MENDONÇA et al., 2004; RIBEIRO et al., 2005; WAGNER JÚNIOR et al., 2006; MENDONÇA et al., 2006b; SOUSA et al., 2008), recipientes (OLIVEIRA et al., 1993; MENDONÇA et al., 2004; RIBEIRO et al., 2005; CHAGAS et al., 2006), adubação (PRADO et al., 2005; ALMEIDA et al., 2006; NATALE et al., 2006; GURGEL et al., 2007; MENDONÇA et al., 2006a; MENDONÇA et al., 2007ab; LIMA et al., 2007; DAVID et al., 2008) e irrigação (VERDIAL et al., 2000; CAVALCANTE et al., 2002; SOUSA et al., 2008) influenciam e proporcionam condições para a propagação inicial do maracujazeiro, pois variações nesses fatores e suas condições podem possibilitar maior ou menor desenvolvimento da planta.

$\mathrm{Na}$ formação de mudas de maracujazeiro, compostos orgânicos não comerciais têm apresentado resultados satisfatórios, tais como, "turfa e bagaço de cana" na proporção de 1:1 (BIASI et al., 1995) e "esterco de curral + casca de café + carvão vegetal + areia + solo" na proporção de 1:1:1:1:2 (MENDONÇA et al., 2004).

Estudos comparando ambientes protegidos na formação de mudas mostram que tipos de material de cobertura, porcentagens de sombreamento e climatização inferem respostas diferenciadas ao desenvolvimento vegetal. Em mudas de maracujá, COSTA et al. (2009) encontraram que a tela de monofilamento, com 50\% de sombreamento, promoveu maior desenvolvimento de plantas que estufa plástica. Em mudas de mamão, ambiente a céu aberto foi mais propício que estufa plástica e viveiro telado (ARAÚJO et al., 2006), assim como mudas de tamarindeiro (MENDONÇA et al., 2008) e mudas de jatobá (CARVALHO FILHO et al., 2003) apresentaram melhor desenvolvimento a céu aberto que em telado com 50\% de sombreamento; no entanto, em Angelim (CARVALHO FILHO et al., 2004) e Canafístola (CARVALHO FILHO et al., 2002), o telado promoveu melhores características às mudas. Em casa de vegetação climatizada, MENDONÇA et al. (2005) obtiveram melhores mudas de mamoeiro "Formosa" que telado com $50 \%$. Níveis de sombreamento com 0; 30 e 50\% não influenciaram na altura e diâmetro do colo de Eriotheca pubescens (CARRIJO et al., 2009), porém, em mudas de turco (Parkinsonia aculeata L.), nível comde $0 \%$ de sombreamento promoveu melhores mudas que o telado com $75 \%$, de acordo com FARIAS JÚNIOR et al. (2007).

Diante do exposto, este trabalho teve como objetivo avaliar diferentes doses de composto orgânico comercial em substrato para a produção de mudas de maracujazeiro, em ambientes protegidos, na região do Pantanal de Aquidauana - MS.

\section{MATERIAL E MÉTODOS}

O experimento com doses de composto orgânico comercial na formação de mudas de maracujazeiro-amarelo, Passiflora edulis Sims f. flavicarpa Deg., foi conduzido na área experimental da Universidade Estadual de Mato Grosso do Sul (UEMS), na Unidade Universitária 
de Aquidauana, que se localiza à altitude de $174 \mathrm{~m}$, longitude de $-55,67^{\circ}$ e latitude de $-20,45^{\circ}$, região de interface entre Cerrado e Pantanal, entre os meses de setembro e dezembro de 2007.

Foram utilizados seis diferentes ambientes protegidos:

1 - (A1) estufa plástica, tipo capela, construída em estrutura de madeira, possuindo dimensões de 5,0 $\mathrm{m}$ de comprimento por 5,0 $\mathrm{m}$ de largura por 2,50 $\mathrm{m}$ de pé-direito, com 3,3 $\mathrm{m}$ de altura no centro; coberta com filme transparente de polietileno de baixa densidade com $150 \mu \mathrm{m}$ de espessura e fechada toda a volta com tela de sombreamento de fios de ráfia na cor preta, malha para $50 \%$ de sombra.

2 - (A2) viveiro telado, em forma de paralelepípedo, construído em estrutura de madeira, possuindo dimensões de 5,0 $\mathrm{m}$ de comprimento por 5,0 $\mathrm{m}$ de largura por 2,50 $\mathrm{m}$ de altura, coberto e com fechamentos em toda a volta com tela de sombreamento de monofilamento, na cor preta (sombrite ${ }^{\circledR}$ ), malha para $50 \%$ de sombra.

3 - (A3) viveiro telado, em forma de paralelepípedo, construído em estrutura de madeira, possuindo dimensões de 5,0 $\mathrm{m}$ de comprimento por 5,0 $\mathrm{m}$ de largura por 2,50 $\mathrm{m}$ de altura, coberto e com fechamentos em toda volta com tela termorefletora aluminizada (aluminet $\AA$ ), malha para $50 \%$ de sombra.

4 - (A4) viveiro em forma de paralelepípedo construído em estrutura de madeira, possuindo dimensões de 3,0 $\mathrm{m}$ de comprimento por 1,20 $\mathrm{m}$ de largura por $1,70 \mathrm{~m}$ de altura em toda a sua extensão, coberto com palha de coqueiro nativo da região, conhecido popularmente como buriti, totalmente aberto nas laterais e frontais.

5 - (A5) estufa agrícola em arcos, com abertura zenital ao longo da cumeeira, construída em estrutura de aço galvanizado; possuindo $6,4 \mathrm{~m}$ de largura por 18,0 $\mathrm{m}$ de comprimento, com altura sob a calha de 4,0 $\mathrm{m}$ e $6,0 \mathrm{~m}$ na cumeeira, coberta com filme de polietileno difusor de luz de $150 \mu \mathrm{m}$. Fechamento, em toda a volta, com tela de monofilamento (sombrite ${ }^{\circledR}$ ), em malha para $50 \%$ de sombreamento. Sombreamento interno móvel, por acionamento manual, com tela aluminizada (aluminet ${ }^{\circledR}$ ) de $50 \%$.

6 - (A6) viveiro telado, em forma de paralelepípedo, construído em estrutura de aço galvanizado com dimensões de $6,40 \mathrm{~m}$ de largura por $18,00 \mathrm{~m}$ de comprimento com 3,50 m de altura em toda a sua extensão, com fechamento em 45 graus, em toda a volta, com tela de monofilamento (sombrite ${ }^{\circledR}$ ), malha para $50 \%$ de sombra.

Foram utilizadas cinco porcentagens de composto orgânico comercial, misturado ao solo local para composição dos diferentes substratos, explicitando:

a) (S1) $100 \%$ de solo e $0 \%$ de composto orgânico;

b) (S2) $93 \%$ de solo e $7 \%$ de composto orgânico;

c) (S3) $86 \%$ de solo e $14 \%$ de composto orgânico;

d) (S4) $79 \%$ de solo e $21 \%$ de composto orgânico;

e) (S5) $72 \%$ de solo e $28 \%$ de composto orgânico.

Para a avaliação do experimento, foi utilizado o delineamento inteiramente casualizado, em esquema de parcelas subdivididas, com dez repetições, sendo as parcelas principais os ambientes de cultivo, e as subparcelas, os substratos.

O solo para o preparo dos substratos foi obtido da área do Câmpus de Aquidauana, da Universidade Estadual de Mato Grosso do Sul, na camada de 10 a $40 \mathrm{~cm}$ (Tabela 1). Utilizou-se o composto orgânico fabricado pela empresa Organoeste, denominado Organosuper ${ }^{\circledR}$, com idade aproximada de dois anos. Aplicaram-se doses de $2,5 \mathrm{~kg}$ de superfosfato simples $\left(\mathrm{P}_{2} \mathrm{O}_{5}\right), 0,3 \mathrm{~kg}$ de cloreto de potássio $(\mathrm{KCl})$ e 1,5 kg de calcário dolomítico (PRNT), por metro cúbico de substrato. Os substratos ficaram em repouso por 30 dias antes da realização da semeadura, dentro dos ambientes, 
para melhor mineralização da matéria orgânica presente no composto orgânico, sendo irrigados manualmente duas vezes ao dia, pela manhã e à tarde.

TABELA 1. Análise química dos substratos (S) utilizados no experimento. Chemical analyses of the substrates $(\mathrm{S})$ used in the experiments.

\begin{tabular}{rccrccccccc}
\hline & $\mathrm{pH}$ & $\mathrm{M} . \mathrm{O}$. & \multicolumn{1}{c}{$\mathrm{P}$} & $\mathrm{K}$ & $\mathrm{Ca}$ & $\mathrm{Mg}$ & $\mathrm{H}+\mathrm{Al}$ & $\mathrm{SB}$ & $\mathrm{T}$ & $\mathrm{V}$ \\
\hline & & $\%$ & $\mathrm{mg} \mathrm{dm}^{-3}$ & & & \multicolumn{7}{c}{$\mathrm{Cmol}_{\mathrm{c}} \mathrm{dm}^{-3}$} & & & $\%$ \\
S1 & 5,4 & 1,4 & 10,5 & 0,35 & 0,9 & 0,8 & 3,3 & 2,05 & 5,35 & 38,32 \\
S2 & 6,0 & 3,2 & 976,1 & 0,64 & 2,3 & 1,5 & 3,0 & 4,44 & 7,44 & 59,68 \\
S3 & 6,4 & 3,7 & 976,1 & 0,94 & 3,2 & 1,9 & 2,7 & 6,04 & 8,74 & 69,11 \\
S4 & 6,5 & 4,7 & 619,2 & 1,53 & 3,3 & 2,4 & 2,2 & 7,23 & 9,43 & 76,67 \\
S5 & 6,3 & 5 & $1.513,1$ & 1,18 & 3,6 & 2,5 & 2,7 & 7,28 & 9,98 & 72,95 \\
\hline
\end{tabular}

Fonte: Laboratório de análises do solo da agência estadual de defesa sanitária animal e vegetal de MS.

Foram coletadas as temperaturas de bulbo seco e bulbo úmido, nos horários de $9 \mathrm{~h}, 12 \mathrm{~h}$ e $15 \mathrm{~h}$ de cada ambiente de produção, no período de 15 de outubro a 13 de dezembro de 2007. Posteriormente, obteve-se a umidade relativa com software Psychrometric Function Demo ${ }^{\circledR}$ (Tabela 2).

TABELA 2. Temperatura $\left({ }^{\circ} \mathrm{C}\right)$ e umidade relativa $(\%)$ nos horários das $9 \mathrm{~h}, 12 \mathrm{~h} \mathrm{e} 15 \mathrm{~h}$ para cada ambiente (A) de produção, durante o desenvolvimento do experimento, em 2007. Temperature $\left({ }^{\circ} \mathrm{C}\right)$ and relative humidity $(\%)$ at 9 AM, 12 PM, and 3 PM for each environment (A) during the experiments in 2007.

\begin{tabular}{cccccccccc}
\hline & TBS & TBU & TBS & TBU & TBS & TBU & \multicolumn{3}{c}{ UR } \\
\hline \multicolumn{1}{c}{ 9h00min } & \multicolumn{2}{c}{ 12h00min } & \multicolumn{1}{c}{ 15h00min } & 9h00min & 12h00min & $15 \mathrm{~h} 00 \mathrm{~min}$ \\
\hline A1 & 30,4 & 25,5 & 34,5 & 27,5 & 37,1 & 28,6 & 69,4 & 60,9 & 56,3 \\
A2 & 29,6 & 25,1 & 33,2 & 27,0 & 36,1 & 27,7 & 72,3 & 64,2 & 56,4 \\
A3 & 30,2 & 26,0 & 33,9 & 28,1 & 36,0 & 29,3 & 73,0 & 67,2 & 63,8 \\
A4 & 28,8 & 25,5 & 32,7 & 26,8 & 35,3 & 27,6 & 78,7 & 66,1 & 59,1 \\
A5 & 29,1 & 24,0 & 33,1 & 25,1 & 34,2 & 25,4 & 67,8 & 54,9 & 52,8 \\
A6 & 30,1 & 25,8 & 33,3 & 27,1 & 34,7 & 27,0 & 72,9 & 64,4 & 58,3 \\
\hline
\end{tabular}

TBS - temperatura de bulbo seco $\left({ }^{\circ} \mathrm{C}\right)$; TBU - temperatura de bulbo úmido $\left({ }^{\circ} \mathrm{C}\right)$; UR - umidade relativa (\%).

A semeadura ocorreu em 24-10-2007 em sacolas de polietileno, nas dimensões de 15,0 x $21,5 \mathrm{~cm}\left(1.540,60 \mathrm{~cm}^{3}\right)$, onde foram colocadas duas sementes por recipiente. No dia 20-11-2007, foi realizado o desbaste, deixando-se uma planta por recipiente. A partir do desbaste, a cada 7 dias, foram mensurados a altura, com régua milimetrada, e o número de folhas definitivas até aos 50 dias após a semeadura (DAS). As datas de coletas de altura foram: 22-11-2007 (29 DAS); 29-11-2007, (36 DAS); 06-12-2007 (43 DAS); 13-12-2007 (50 DAS) (MENDONÇA et al., 2004).

Aos 50 DAS, foram coletadas a massa fresca e a massa seca da parte aérea e de raízes. A massa fresca foi pesada em balança analítica e, posteriormente, levada à estufa para secagem num processo de obtenção da massa seca, pelo método do peso constante. Os dados foram submetidos à análise de variância, e as médias, ao teste de Tukey, a 5\% de probabilidade, utilizando o software ESTAT (1994).

\section{RESULTADOS E DISCUSSÃO}

Para todas as coletas de altura $(29 ; 36 ; 43$ e 50 DAS) e todos os parâmetros de biomassa, o ambiente A5 apresentou os maiores valores (Tabela 3). Nesse ambiente, sob o filme de polietileno, havia cortina termorrefletora (Aluminet ${ }^{\circledR}$ ), malha para $50 \%$ de sombra, evidenciando que as espécies respondem de maneira distinta ao tipo de sombreamento, pois PINTO et al. (2007) encontraram que telado aluminizado, com $40 \%$ de sombra, promoveu maior acúmulo de matéria 
seca em plantas de alfazema-do-Brasil, que telado com níveis de sombra de $80 \%$. COSTA et al. (2009) encontraram que a tela de monofilamento com $50 \%$ de sombreamento promoveu plantas mais desenvolvidas que a estufa, porém a estufa possuía menores dimensões, sem abertura zenital e sem aluminet ${ }^{\circledR}$ sob o filme.

Os substratos S4, S3 e S2 promoveram maiores massas foliares, tanto frescas como secas, contudo as biomassas radiculares apresentaram maior acúmulo com a utilização dos substratos $\mathrm{S} 2 \mathrm{e}$ S3, mesmo resultado encontrado para as alturas de plantas aos 29; 36 e 43 DAS. Em síntese, verifica-se que os substratos com $7 \%$ e $14 \%$ de composto orgânico comercial apresentaram melhores condições para o desenvolvimento das mudas de maracujá (Tabela 3).

TABELA 3. Altura de plantas (AP) aos 29; 36; 43 e 50 DAS (cm), massa fresca da parte aérea (MFA), massa seca da parte aérea (MSA), massa fresca do sistema radicular (MFR), massa seca do sistema radicular (MSR) para as parcelas (ambientes - A) e subparcelas (substratos - S) do maracujazeiro, aos 50 DAS. Height of plants at 29, 36, 43, and 50 DAS (Days After Seeding) (cm)); fresh mass of aerial part (MFA); dry mass of aerial part (MSA); fresh mass of the rooting system (MFR); dry mass of the rooting system (MSR) to the principal plots (Environment - A), and subplots (substrate -S) for the passiflora seedlings at $50 \mathrm{DAS}$.

\begin{tabular}{ccccccccc}
\hline & 29 DAS & 36 DAS & 43DAS & 50DAS & MFA $(\mathrm{g})$ & MSA $(\mathrm{g})$ & MFR $(\mathrm{g})$ & MSR $(\mathrm{g})$ \\
\hline $\mathrm{A} 1$ & $4,08 \mathrm{C}$ & $5,80 \mathrm{C}$ & $6,98 \mathrm{D}$ & $11,70 \mathrm{~B}$ & $4,45 \mathrm{BC}$ & $0,76 \mathrm{D}$ & $2,92 \mathrm{C}$ & $0,43 \mathrm{~B}$ \\
$\mathrm{~A} 2$ & 5,12 B & $7,25 \mathrm{~B}$ & $9,51 \mathrm{BC}$ & $13,00 \mathrm{AB}$ & $3,77 \mathrm{C}$ & $0,92 \mathrm{CD}$ & $2,15 \mathrm{D}$ & $0,40 \mathrm{~B}$ \\
$\mathrm{~A} 3$ & $4,88 \mathrm{~B}$ & $7,18 \mathrm{~B}$ & $8,71 \mathrm{BC}$ & $13,70 \mathrm{AB}$ & $4,56 \mathrm{BC}$ & $1,04 \mathrm{BC}$ & $3,70 \mathrm{~B}$ & $0,46 \mathrm{~B}$ \\
A4 & $4,71 \mathrm{~B}$ & $7,24 \mathrm{~B}$ & $8,32 \mathrm{C}$ & $12,50 \mathrm{~B}$ & $5,09 \mathrm{~B}$ & $1,17 \mathrm{~B}$ & $3,92 \mathrm{~B}$ & $0,46 \mathrm{~B}$ \\
A5 & $5,91 \mathrm{~A}$ & $8,12 \mathrm{~A}$ & $11,72 \mathrm{~A}$ & $15,05 \mathrm{~A}$ & $7,33 \mathrm{~A}$ & $1,71 \mathrm{~A}$ & $4,66 \mathrm{~A}$ & $0,60 \mathrm{~A}$ \\
$\mathrm{~A} 6$ & $5,22 \mathrm{~B}$ & $7,58 \mathrm{AB}$ & $9,77 \mathrm{~B}$ & $13,29 \mathrm{AB}$ & $5,24 \mathrm{~B}$ & $1,16 \mathrm{~B}$ & $3,50 \mathrm{BC}$ & $0,48 \mathrm{~B}$ \\
\hline $\mathrm{C} . \mathrm{V} .(\%)$ & 14,45 & 13,61 & 16,63 & 16,24 & 20,13 & 22,08 & 22,61 & 24,00 \\
\hline S1 & $4,81 \mathrm{BC}$ & $7,67 \mathrm{~B}$ & $8,58 \mathrm{~B}$ & $10,93 \mathrm{C}$ & $3,62 \mathrm{~B}$ & $0,79 \mathrm{~B}$ & $2,56 \mathrm{C}$ & $0,42 \mathrm{~B}$ \\
S2 & $5,66 \mathrm{~A}$ & $7,91 \mathrm{~A}$ & $9,99 \mathrm{~A}$ & $13,84 \mathrm{~B}$ & $6,07 \mathrm{~A}$ & $1,35 \mathrm{~A}$ & $4,55 \mathrm{~A}$ & $0,61 \mathrm{~A}$ \\
S3 & $5,36 \mathrm{AB}$ & $8,20 \mathrm{~A}$ & $10,48 \mathrm{~A}$ & $15,42 \mathrm{~A}$ & $6,27 \mathrm{~A}$ & $1,35 \mathrm{~A}$ & $4,86 \mathrm{~A}$ & $0,60 \mathrm{~A}$ \\
S4 & $4,70 \mathrm{C}$ & $6,49 \mathrm{~B}$ & $8,78 \mathrm{~B}$ & $13,31 \mathrm{~B}$ & $5,41 \mathrm{~A}$ & $1,21 \mathrm{~A}$ & $3,21 \mathrm{~B}$ & $0,43 \mathrm{~B}$ \\
S5 & $4,41 \mathrm{C}$ & $6,36 \mathrm{~B}$ & $8,02 \mathrm{~B}$ & $12,51 \mathrm{~B}$ & $4,00 \mathrm{~B}$ & $0,91 \mathrm{~B}$ & $2,20 \mathrm{C}$ & $0,30 \mathrm{C}$ \\
\hline C.V. $(\%)$ & 15,87 & 14,51 & 18,24 & 13,94 & 24,88 & 24,32 & 23,98 & 20,50 \\
\hline
\end{tabular}

* Médias seguidas de mesma letra, na coluna, não diferem entre si, pelo teste de Tukey, a 5\% de probabilidade.

Por meio da análise de variância, verificou-se que altura de plantas aos 43 e 50 DAS e a massa fresca da parte aérea (MFF) não apresentaram interações entre ambientes e substratos. Os resultados das alturas e dos parâmetros de biomassa são referentes aos efeitos das parcelas, subparcelas e subsubparcelas e como estes foram significativos (Tabela 3). Os interesses da avaliação voltaram-se para os desdobramentos e as respostas das interações entre ambientes e substratos (Tabelas 4 e 5 ).

Nos ambientes A1, A4 e A6, aos 29 DAS, e nos ambientes A3 e A4, aos 36 DAS, as plantas apresentaram alturas similares nos diferentes substratos. O substrato S3, com 14\% de composto orgânico comercial, não diferiu para a altura de plantas dos substratos S2 e S4, no ambiente A2, aos 29 e 36 DAS; dos substratos S1 e S2 no ambiente A3, aos 29 DAS; dos substratos S1, S2 e S4, nos ambientes A4 e A5, aos 29 DAS e 36 DAS, respectivamente, e do substrato S2, no ambiente A6, aos 36 DAS. Esse substrato (S3) proporcionou plantas maiores quando no ambiente A1, aos 36 DAS (Tabela 4). Para o substrato S5, aos 29 DAS, e para o S4, aos 36 DAS, os ambientes de cultivo apresentaram plantas com alturas semelhantes. Para o substrato S1, o melhor ambiente foi o A5, aos 29 e 36 DAS. Para os demais substratos, o ambiente A1 apresentou as menores plantas (Tabela 4).

Esperava-se que doses crescentes de substrato orgânico promovessem melhor crescimento e desenvolvimento da planta, fato não observado, possivelmente, pela não uniformização do composto orgânico comercial (Tabela 1 e Tabela 3). MENDONÇA et al. (2004), utilizando doses 
crescentes de Osmocote ${ }^{\circledR}$ (15-10-10), que é um fertilizante de liberação controlada, sendo composto de nutrientes encapsulados com resina orgânica biodegradável, projetado para nutrir a cultura durante todo o seu ciclo de crescimento, verificaram que doses crescentes desse composto foram proporcionais aos maiores crescimentos e acúmulo de biomassas, encontrando que $12 \mathrm{kgm}^{-3}$ propiciaram mudas de maracujá-amarelo de melhor qualidade.

Doses de 0; 2; 4; 6 e $8 \mathrm{kgm}^{-3}$ de lithothamnium (Concinal Fertilizador ${ }^{\circledR}$ ), uma alga marinha calcárea, com aproximadamente $65 \%$ de cálcio e $25 \%$ de magnésio, possuindo traços de ferro, fósforo, sódio, potássio, iodo, cloro, entre outros, foram adicionados a vários substratos em sacos de polietileno com capacidade de $500 \mathrm{~mL}$, observando que dosagens até $4,5 \mathrm{kgm}^{-3}$ proporcionaram bons resultados na formação de mudas de maracujazeiro-amarelo, aos 126 DAS (MENDONÇA et al., 2006b), verificando que o composto orgânico foi superior ao Plantimax ${ }^{\circledR}$.

Substrato à base de "esterco bovino + solo, na proporção de 1:3 v/v", foi enriquecido com doses de fertilizante de liberação lenta (Entec: $0 ; 3 ; 6 ; 9$ e $12 \mathrm{kgm}^{-3}$ ), verificando que dosagens de até $6 \mathrm{kgm}^{-3}$ promoveram mudas de qualidade de maracujazeiro-amarelo, aos 120 DAS, e dosagens elevadas causam efeitos depressivos nas mudas (MENDONÇA et al., 2007b).

TABELA 4. Desdobramentos das alturas de plantas (AP) dos substratos (S) dentro dos ambientes (A) e dos ambientes (A) dentro dos substratos (S) aos 29 e 36 DAS. Spread out of plants height (AP) of substrates (S) within the environments (A), and the environments (A) within the substrates (S) at 29 and 36 DAS.

\begin{tabular}{lllllll}
\hline \multicolumn{7}{c}{$29 \mathrm{DAS}$} \\
\hline & \multicolumn{1}{c}{$\mathrm{A} 1$} & $\mathrm{~A} 2$ & $\mathrm{~A} 3$ & \multicolumn{1}{c}{$\mathrm{A} 4$} & \multicolumn{1}{c}{$\mathrm{A} 5$} & \multicolumn{1}{c}{$\mathrm{A} 6$} \\
$\mathrm{~S} 1$ & $3,26 \mathrm{Ac}$ & $4,06 \mathrm{Bbc}$ & $5,02 \mathrm{ABCb}$ & $4,56 \mathrm{Abc}$ & $6,90 \mathrm{Aa}$ & $5,06 \mathrm{Ab}$ \\
$\mathrm{S} 2$ & $4,32 \mathrm{Ab}$ & $6,08 \mathrm{Aa}$ & $6,12 \mathrm{Aa}$ & $5,42 \mathrm{Aab}$ & $6,48 \mathrm{Aa}$ & $5,54 \mathrm{Aab}$ \\
$\mathrm{S} 3$ & $4,38 \mathrm{Ac}$ & $6,16 \mathrm{Aa}$ & $5,28 \mathrm{ABabc}$ & $4,52 \mathrm{Abc}$ & $5,84 \mathrm{ABab}$ & $5,98 \mathrm{Aa}$ \\
$\mathrm{S} 4$ & $4,22 \mathrm{Ab}$ & $4,78 \mathrm{ABab}$ & $4,22 \mathrm{BCb}$ & $4,50 \mathrm{Aab}$ & $5,86 \mathrm{Aa}$ & $4,90 \mathrm{Aab}$ \\
$\mathrm{S} 5$ & $4,22 \mathrm{Aa}$ & $4,52 \mathrm{Ba}$ & $3,78 \mathrm{Ca}$ & $4,56 \mathrm{Aa}$ & $4,46 \mathrm{Ba}$ & $4,62 \mathrm{Aa}$ \\
\hline \multicolumn{7}{c}{$36 \mathrm{DAS}$} \\
$\mathrm{S} 1$ & $5,54 \mathrm{Bb}$ & $6,50 \mathrm{Bb}$ & $6,90 \mathrm{Ab}$ & $7,28 \mathrm{ABab}$ & $9,04 \mathrm{Aa}$ & $6,78 \mathrm{Bb}$ \\
$\mathrm{S} 2$ & $5,64 \mathrm{Bb}$ & $7,78 \mathrm{ABa}$ & $8,08 \mathrm{Aa}$ & $8,46 \mathrm{Aa}$ & $9,54 \mathrm{Aa}$ & $7,98 \mathrm{ABa}$ \\
$\mathrm{S} 3$ & $7,50 \mathrm{Ab}$ & $8,54 \mathrm{Aab}$ & $7,62 \mathrm{Aab}$ & $7,56 \mathrm{ABab}$ & $8,58 \mathrm{ABab}$ & $9,40 \mathrm{Aa}$ \\
$\mathrm{S} 4$ & $5,28 \mathrm{Ba}$ & $6,76 \mathrm{ABa}$ & $6,98 \mathrm{Aa}$ & $6,72 \mathrm{ABa}$ & $6,94 \mathrm{BCa}$ & $6,24 \mathrm{Ba}$ \\
$\mathrm{S} 5$ & $5,04 \mathrm{Bb}$ & $6,66 \mathrm{Bab}$ & $6,30 \mathrm{Aab}$ & $6,16 \mathrm{Bab}$ & $6,52 \mathrm{Cab}$ & $7,48 \mathrm{Ba}$ \\
\hline
\end{tabular}

*Letras iguais maiúsculas nas colunas e minúsculas nas linhas não diferem entre si, pelo teste de Tukey, a 5\% de probabilidade.

Não houve interação significativa entre ambientes e substratos para a MFF. Para a MSF, os substratos não diferiram no ambiente A1. No ambiente A2, o substrato S2 apresentou-se superior ao substrato S5. Nos ambientes A3 e A5, o substrato S4 foi superior aos substratos S1 e S5. Nos ambientes A4 e A6, o substrato $S 3$, que não diferiu do substrato $S 2$, promoveu maiores acúmulos de biomassa foliar que os substratos S1 e S5 (Tabela 5).

Verifica-se que os substratos com $7 ; 14$ e $21 \%$ de composto orgânico na composição dos substratos apresentaram maiores MSF que os substratos sem composto e com maior percentagem. As percentagens intermediárias podem ser um bom indicativo da quantidade de composto que se deve utilizar na formulação de substratos quando misturados com solos da região.

Para o substrato S1, o ambiente A5 propiciou maior MSF que os ambientes A1 e A3. No substrato S2, esse ambiente foi superior aos ambientes A1 e A2, já no substrato S3 foi superior aos ambientes A1, A2 e A3, enquanto no substrato S4 foi superior a todos os demais, e no substrato S5, foi superior aos ambientes A1, A2, A3 e A4 (Tabela 5).

Nos ambientes A1 e A2, os substratos praticamente não diferiram para a MFR, destacando, apenas, que no ambiente A1, o substrato S3 foi superior ao substrato S5. Nos demais ambientes, 
verificou-se que o substrato S3 se destacou, sendo que no ambiente A3 foi superior a todos os substratos; nos ambientes A4 e A6, esse substrato, que não diferiu do substrato S2, foi superior aos demais, onde no ambiente A5 foi superior apenas aos substratos S1 e S5 (Tabela 5). No substrato $\mathrm{S} 1$, os ambientes A4 e A5 propiciaram maior MFR que o ambiente A6. Para o substrato S2, o ambiente A5 propiciou maior valor que os ambientes A1, A2 e A3; já no S3, foi superior apenas ao A1 e A2. Para o S4, esse ambiente foi superior aos ambientes A1, A2 e A4, sendo que, no substrato S5, os ambientes não diferiram (Tabela 5).

Para a MSR nos ambientes A1, A4 e A6, os substratos S2 e S3 apresentaram maior acúmulo de biomassa que os substratos $\mathrm{S} 1$ e $\mathrm{S} 5$. No ambiente A2, os substratos $\mathrm{S} 1$ e $\mathrm{S} 2$ promoveram maior MSR que o substrato S5. No ambiente A3, o substrato S3, que não diferiu do substrato S2 e S4, apresentou-se superior aos substratos S1 e S5, sendo que, no ambiente A5, esse substrato superou os demais (Tabela 5).

Para o substrato S1, no parâmetro de MSR, os ambientes A2 e A5 promoveram resultados superiores aos demais ambientes. No substrato S2 os ambientes A1 e A5 se destacaram. No substrato S3, o ambiente A2, que não diferiu do ambiente A4, apresentou menores valores de MSR que os demais ambientes. No substrato S4, o ambiente A5 foi superior aos ambientes A2 e A4, e, no substrato S5, esse ambiente foi superior aos ambientes A1 e A3.

Aos 48 DAS, em recipiente plástico com capacidade de 1 litro de substrato, no interior de casa de vegetação aos 48 DAS, WAGNER JÚNIOR et al. (2006) obtiveram massa seca total (0,15 g) inferior à obtida neste experimento em todos os ambientes de cultivo. Em Ji-Paraná-RO, aos 90 DAS, ZANELLA et al. (2006), testando 0; 30; 50 e 80\% de sombreamento, obtiveram maior acúmulo de biomassa seca total $(1,98 \mathrm{~g})$ no sombreamento com $80 \%$, sendo inferior aos resultados obtidos pelos substratos $\mathrm{S} 2$ (2,10; 2,54 e 1,99 g) e $\mathrm{S} 3$ (2,17; 2,50 e 2,35 g) nos ambientes A4, A5 e A6, respectivamente, e também no substrato S4 (2,61 g), no ambiente A5 (Tabela 5).

Em ambiente climatizado, utilizando "Plantimax, casca de café, pó de serra, areia e solo, na proporção de 1:1:1:1: 2 v/v" em sacolas de $500 \mathrm{~mL}$, MENDONÇA et al. (2005) obtiveram, aos 85 DAS, altura de planta $(25,71 \mathrm{~cm})$ e massa seca da parte aérea $(2,45 \mathrm{~g})$ superiores aos encontrados em Aquidauana - MS (15,05 cm e 2,05 g, respectivamente) aos 50 DAS, em estufa agrícola (A5) e substrato com $21 \%$ de composto orgânico (S4), onde a idade de avaliação e o ambiente de cultivo propiciaram mudas maiores, com maior biomassa.

Sendo um dos melhores ambientes de cultivo de maracujazeiro-amarelo, a estufa agrícola com pé-direito de 4,0 m, abertura zenital e cortina sob o filme (Aluminet ${ }^{\circledR} 50 \%$ ), apresentou as menores umidades relativas, provavelmente devido à maior evapotranspiração que poderia estar ocorrendo nesse ambiente. A menor estufa (A1) apresentou temperatura superior à maior estufa (A5), provavelmente, devido a sua configuração, sem abertura zenital e sem tela sob o plástico, e por possuir menor volume de ar internamente, o que facilitava as trocas gasosas internas e externas, promovendo maior umidade relativa (Tabela 2). No ambiente A1, pé-direito baixo e ausência de abertura na cumeeira, o filme de PEBD propiciou maiores temperaturas devido ao efeito estufa, concordando com CUNHA \& ESCOBEDO (2003) e COSTA et al. (2004). O maior viveiro agrícola (A6) promoveu melhores plantas que o viveiro agrícola menor (A2), onde, às $15 \mathrm{~h}$, esse ambiente (A6) apresentou temperatura inferior à apresentada no ambiente A2, revelando que ambientes telados com maior volume de ar podem apresentar temperaturas máximas menores (Tabela 2).

Os diferentes materiais nas coberturas dos ambientes podem ter proporcionado alterações no microclima interno (SENTELHAS et al., 1998) e terem interferido nas respostas das plantas aos processos fisiológicos, como fotossíntese e transpiração (ZANELLA et al., 2006). Mesmo assim, as temperaturas nos horários das $9 \mathrm{~h}, 12 \mathrm{~h}$ e $15 \mathrm{~h}$ de cada ambiente de cultivo de mudas foram similares e não afetaram o gradiente de temperatura, conforme observado por PEZZOPANE et al. (2004), em telas com diferentes percentagens de sombreamento (Tabela 2). 
A altura de planta $(13,29 \mathrm{~cm})$ no viveiro telado com sombrite ${ }^{\circledR} 50 \%$ A6 (Tabela 3) foi similar à altura $(14,0 \mathrm{~cm})$ encontrada por PIO et al. (2004) aos 60 DAS em ambiente semelhante, no qual os autores recomendam adição de, no máximo, $33 \%$ de matéria orgânica em formulações de substratos com terra, areia e esterco. Contudo, através dos resultados obtidos neste experimento, pode-se recomendar adição de, no máximo, $21 \%$ de composto orgânico comercial em formulações de substratos para obtenção de mudas de qualidade. RIBEIRO et al. (2005) recomendam sacolas de polietileno de $20,0 \mathrm{~cm}$ x $5,5 \mathrm{~cm}$, onde aos 30 DAS, em casa de vegetação, utilizando "solo + esterco de bovino, proporção 1:1 em volume", encontraram biomassas foliares e radiculares menores que as encontradas neste experimento em Aquidauana - MS, porém obtiveram alturas maiores.

TABELA 5. Desdobramento da massa fresca da parte aérea (MFA), massa seca da parte aérea (MSA), massa fresca do sistema radicular (MFR), massa seca do sistema radicular (MSR) dos substratos (S) dentro dos ambientes (A) e dos ambientes (A) dentro dos substratos (S) aos 50 DAS. . Spread out of the fresh mass of the aerial part (MFA), dry mass of the aerial part (MAS), fresh mass of the rooting system (MFR), and dry mass of the rooting system (MSR) of substrates (S) within the environments (A), and of the environments (A) within the substrates (S) at 50 DAS.

\begin{tabular}{|c|c|c|c|c|c|c|}
\hline \multicolumn{7}{|c|}{ Matéria Fresca Radicular - gramas } \\
\hline & A1 & $\mathrm{A} 2$ & A3 & A4 & A5 & A6 \\
\hline S1 & 2,806 ABab & $2,021 \mathrm{Aab}$ & 2,234 Cab & $3,325 \mathrm{Ba}$ & $3,498 \mathrm{Ba}$ & $1,452 \mathrm{Bb}$ \\
\hline S2 & 3,659 Acd & $2,617 \mathrm{Ad}$ & $4,146 \mathrm{Bbc}$ & 5,181 Aab & $6,147 \mathrm{Aa}$ & 5,558 Aab \\
\hline S3 & $3,489 \mathrm{Ab}$ & $2,458 \mathrm{Ab}$ & $6,057 \mathrm{Aa}$ & $5,775 \mathrm{Aa}$ & $5,801 \mathrm{Aa}$ & $5,553 \mathrm{Aa}$ \\
\hline S4 & 2,792 ABbc & $2,100 \mathrm{Ac}$ & 3,957 Bab & $2,622 \mathrm{Bbc}$ & 5,057 Aa & 2,704 Bbc \\
\hline S5 & $1,841 \mathrm{Ba}$ & $1,532 \mathrm{Aa}$ & $2,104 \mathrm{Ca}$ & $2,679 \mathrm{Ba}$ & 2,779 Ba & $2,251 \mathrm{Ba}$ \\
\hline \multicolumn{7}{|c|}{ Matéria Seca Aérea - gramas } \\
\hline $\mathrm{S} 1$ & $0,614 \mathrm{Ab}$ & $0,836 \mathrm{ABab}$ & $0,707 \mathrm{Bb}$ & $0,694 \mathrm{Cb}$ & $1,321 \mathrm{Ca}$ & $0,611 \mathrm{Cb}$ \\
\hline S2 & $0,883 \mathrm{Ac}$ & $1,235 \mathrm{Abc}$ & 1,370 Aabc & $1,499 \mathrm{Aab}$ & $1,729 \mathrm{ABCa}$ & $1,405 \mathrm{ABab}$ \\
\hline S3 & $0,911 \mathrm{Ac}$ & $0,994 \mathrm{ABc}$ & $1,098 \mathrm{ABbc}$ & 1,581 Aab & $1,867 \mathrm{ABa}$ & 1,673 Aa \\
\hline $\mathrm{S} 4$ & 0,788 Ac & $0,891 \mathrm{ABbc}$ & $1,342 \mathrm{Ab}$ & $1,178 \mathrm{ABbc}$ & $2,050 \mathrm{Aa}$ & $1,020 \mathrm{BCbc}$ \\
\hline S5 & $0,596 \mathrm{Ab}$ & $0,660 \mathrm{Bb}$ & $0,663 \mathrm{Bb}$ & $0,899 \mathrm{BCb}$ & $1,563 \mathrm{BCa}$ & 1,085 BCab \\
\hline \multicolumn{7}{|c|}{ Matéria Seca Radicular - gramas } \\
\hline S1 & $0,290 \mathrm{BCc}$ & 0,482 Aab & 0,404 Bbc & 0,408 Bbc & $0,599 \mathrm{Ba}$ & $0,326 \mathrm{Cbc}$ \\
\hline $\mathrm{S} 2$ & 0,631 Aab & $0,462 \mathrm{Ab}$ & $0,538 \mathrm{ABb}$ & $0,604 \mathrm{Ab}$ & $0,814 \mathrm{Aa}$ & $0,588 \mathrm{ABb}$ \\
\hline S3 & $0,638 \mathrm{Aa}$ & $0,419 \mathrm{ABb}$ & $0,643 \mathrm{Aa}$ & 0,586 Aab & 0,635 Ba & $0,6744 \mathrm{Aa}$ \\
\hline S4 & 0,390 Bab & $0,350 \mathrm{ABb}$ & 0,510 ABab & 0,353 Bb & $0,560 \mathrm{BCa}$ & 0,437 BCab \\
\hline S5 & $0,174 \mathrm{Cc}$ & $0,267 \mathrm{Babc}$ & $0,224 \mathrm{Cbc}$ & $0,370 \mathrm{Bab}$ & $0,409 \mathrm{Ca}$ & $0,374 \mathrm{Cab}$ \\
\hline
\end{tabular}

*Letras iguais maiúsculas nas colunas e minúsculas nas linhas não diferem entre si, pelo teste de Tukey, a 5\% de probabilidade.

\section{CONCLUSÕES}

A estufa agrícola, com abertura zenital, sombreamento com aluminete ${ }^{\circ} 50 \%$ sob a cobertura, o viveiro agrícola com pé-direito de $3,5 \mathrm{~m}$ e tela de sombreamento Sombrite ${ }^{\circledR} 50 \%$, e o viveiro coberto com palha de coqueiro nativo propiciaram maior acúmulo de biomassa, promovendo os melhores ambientes para o desenvolvimento do maracujazeiro-amarelo.

Os substratos com 7\%, $14 \%$ e $21 \%$ de composto orgânico mostraram-se viáveis para composição de substratos com solo da região de Aquidauana, para a produção de mudas de maracujazeiro.

Os substratos com porcentagem de composto orgânico acima de $21 \%$ e sem composto orgânico mostraram-se inadequados para o desenvolvimento das mudas de maracujazeiro-amarelo. 


\section{AGRADECIMENTOS}

À Pró-Reitoria de Pesquisa e Pós-Graduação (PROPP) da Universidade Estadual de Mato Grosso do Sul (UEMS), pelos recursos de auxílio à pesquisa, concedidos aos projetos de Iniciação Científica, tornando possível a realização deste trabalho.

\section{REFERÊNCIAS}

ALMEIDA, A. Composto de lixo urbano na composição química do solo e seus efeitos no desenvolvimento de mudas de maracujazeiro-amarelo. Revista de Biociências, Taubaté, v.9, n.2, p.7-15, 2003.

ALMEIDA, E.V.; NATALE, W.; PRADO, R.M.; BARBOSA, J.C. Adubação nitrogenada e potássica no desenvolvimento de mudas de maracujazeiro. Ciência Rural, Santa Maria, v.36, n.4, p.1.138-1.142, 2006.

ARAÚJO, J.G.; ARAÚJO JÚNIOR, M.M.; MENEZES, R.H.N.; MARTINS, M.R.; LEMOS, R.N.S.; CERQUEIRA, M.C. Efeito do recipiente e ambiente de cultivo sobre o desenvolvimento de mudas de mamoeiro cv. sunrise solo. Revista Brasileira de Fruticultura, Jaboticabal, v.28, n.3, p.526-529, 2006.

BIASI, L.A.; BILIA, D.A.C.; SÃO JOSÉ, A.R.; FORNASIERI, J.L.; MINAMI, K. Efeito de misturas de turfa e bagaço de cana sobre a produção de mudas de maracujá e tomate. Scientia Agrícola, Piracicaba, v.52, n.2, p.239-243, 1995.

CARRIJO, C.; MARTINS, R.C.C.; MARTINS, I.S.; LANDAHL, D.T.; MATOS, J.M. de M.; NAKANO, T.Y.R. Estabelecimento de Eriotheca pubescens (Bombacaceae) por meio de semeadura direta e de mudas em cascalheira. CERNE, Lavras, v.15, n.3, p.365-370, 2009.

CARVALHO FILHO, J.L.S. de; ARRIGONI-BLANK, M. de F.; BLANK, A.F. Produção de mudas de angelim (Andira fraxinifolia Benth.) em diferentes ambientes, recipientes e composições de substratos. Revista Ciência Agronômica, Fortaleza, v.35, n.1, p.61-67, 2004.

CARVALHO FILHO, J.L.S. de; ARRIGONI-BLANK, M. de F.; BLANK, A.F.; RANGEL, M.S.A. Produção de mudas de jatobá (Hymenaea courbaril L.) em diferentes ambientes, recipientes e composições de substratos. CERNE, Lavras, v.9, n.1, p.111-121, 2003.

CARVALHO FILHO, J.L.S. de; ARRIGONI-BLANK, M. de F.; BLANK, A.F.; SANTOS NETO, A.L. dos; AMANCIO, V.F. Produção de mudas de Cassia grandis L. em diferentes, recipientes e misturas de substratos. Revista Ceres, Viçosa - MG, v.49, n.284, p.341-352, 2002.

CAVALCANTE, L.F.; SANTOS, J.B.; SANTOS, C.J.O.; FEITOSA FILHO, J.C.; LIMA, E.M.; CAVALCANTE, Í.H.L. Germinação de sementes e crescimento inicial de maracujazeiros irrigados com água salina em diferentes volumes de substrato. Revista Brasileira de Fruticultura, Jaboticabal, v.24, n.3, p.748-751, dez. 2002.

CHAGAS, I.M.; TAVARES, J.C.; FREITAS, R.S.; RODRIGUES, G.S.O. Formação de mudas de maracujá amarelo em quatro tamanhos de recipiente. Revista Verde, Mossoró, v.1, n.2, p.122-133, 2006.

COSTA, E.; LEAL, P.M.; CARMO JÚNIOR, R.R. Modelo de simulação da temperatura e umidade relativa do ar no interior da estufa plástica. Revista Engenharia Agrícola, Jaboticabal, v.24, n.1, p.57-67, 2004.

COSTA, E.; RODRIGUES E.T.; ALVES, V.B.; SANTOS, L.C.R.; VIEIRA, L.C.R. Efeitos da ambiência, recipientes e substratos no desenvolvimento de mudas de maracujazeiro-amarelo em Aquidauana - MS. Revista Brasileira de Fruticultura, Jaboticabal, v.31, n.1, p.236-244, 2009. 
CUNHA, A.R.; ESCOBEDO, J.F. Alterações micrometeorológicas causadas pela estufa plástica e seus efeitos no crescimento e produção da cultura de pimentão. Revista Brasileira de Agrometeorologia, Santa Maria, v.11, n.1, p.15-27, 2003.

DAVID, M.A.; MENDONCA, V.; REIS, L.L.; SILVA, E.A.; TOSTA, M.S.; FREIRE, P.A. Efeito de doses de superfosfato simples e de matéria orgânica sobre o crescimento de mudas de maracujazeiro-amararelo. Pesquisa Agropecuária Tropical, Goiânia, v.38, p.147-152, 2008.

ESTAT. Sistema para análises estatísticas (v. 2.0). Jaboticabal: Departamento de Ciências Exatas, FCAV-UNESP, 1994.

GONÇALVES, J.S.; SOUZA, S.A.M. Fruta da paixão: panorama econômico do maracujá no Brasil. Informações Econômicas, São Paulo, v.36, n.12, dez. 2006.

GURGEL, R.L.S.; SOUZA, H.A.; TEIXEIRA, G.A.; MENDONCA, V.; FERREIRA, E A. Adubação fosfatada e composto orgânico na produção de mudas de maracujazeiro-amarelo. Revista Brasileira de Ciências Agrárias, Recife, v.2, p.262-267, 2007.

FARIAS JÚNIOR, J.A.; CUNHA, M.C.L.; FARIAS, S.G.G.; MENEZES JÚNIOR, J.C.

Crescimento inicial de mudas de turco sob diferentes tipos de recipientes e níveis de luminosidade. Revista Brasileira de Ciências Agrárias, Recife, v.2, n.3, p.228-232, 2007

IBGE. INSTITUTO BRASILEIRO DE GEOGRAFIA E ESTATÍSTICA.Estado@. Lavoura permanente 2008: Maracujá. Brasília: IBGE, 2008. Disponível em:

$<$ http://www.ibge.gov.br/estadosat/temas.php?sigla=df\&tema=lavourapermanente2008>. Acesso em: 16 dez. 2009.

KOSOSKI. R.M.; PEIXOTO, J.R.; JUNQUEIRA, N.T.V.; UESUGI, C.H.; MELO, B. Reação de genótipos de maracujazeiro-azedo a Xanthomonas Campestris pv. Passiflorae, em casa de vegetação. Bioscience Journal, Uberlândia, v.24, n.1, p.60-66, 2008.

LIMA, R.A.R.; MENDONCA, V.; TOSTA, M.S.; REIS, L.L.; BISCARO, G.A.; CHAGAS, E.A. Fósforo e zinco no crescimento de mudas de maracujazeiro-amarelo. Pesquisa Agropecuária Tropical, Goiânia, v.37, p.251-256, 2007.

MENDONCA, V.; RAMOS, J.D.; GONTIJO, T.C.A.; MARTINS, P.C.C.; DANTAS, D.J.; PIO, R.; ARRUDA, N.A.A. Osmocote e substratos alternativos na produção de mudas de maracujazeiroamarelo. Ciência e Agrotecnologia, Lavras, v.28, n.4, p.799-806, 2004.

MENDONCA, V.; RAMOS, J.D.; RUFINI, J.C.M.; PIO, R.; CARRIJO, E.P.; GONTIJO, T.C.A. Diferentes substratos e ambientes na formação de mudas de maracujazeiro-amarelo. Revista Científica Rural, Bagé, v.10, n.2, p.10-15, 2005.

MENDONCA, V.; ARAUJO NETO, S.E.; RAMOS, J.D.; CARVALHO, J.G.; ANDRADE JÚNIOR, V.C. Fontes e doses de fósforo para o maracujazeiro-amarelo. Caatinga, Mossoró, v.9, p.65-70, 2006a.

MENDONCA, V.; ORBES, M.Y.; ARRUDA, N.A.A.; RAMOS, J.D.; TEIXEIRA, G.A.; SOUZA, H.A. Qualidade de mudas de maracujazeiro-amarelo formadas em substratos com diferentes níveis de Lithothamniun. Ciência e Agrotecnologia, Lavras, v.30, p.900-906, 2006 b.

MENDONCA, V.; FERREIRA, E.A.; PAULA, Y.C.M.; BATISTA, T.M.V.; RAMOS, J.D. Crescimento de mudas de maracujazeiro-amarelo influenciado por doses de nitrogênio e de superfosfato simples. Caatinga, Mossoró, v.20, p.137-143, 2007 a.

MENDONCA, V.; TOSTA, M.S.; MACHADO, J.R.; GOULART JÚNIOR, S.A.R.; TOSTA, J.S.; BISCARO, G.A. Fertilizante de liberação lenta na formação de mudas de maracujazeiro-amarelo. Ciência e Agrotecnologia, Lavras, v.31, n.2, p.344-348, $2007 \mathrm{~b}$. 
MENDONCA, V.; ARRUDA, N.A.A.; SOUZA, H.A.; TEIXEIRA, G.A.; HAFLE, O.M.; RAMOS, J.D. Diferentes ambientes e osmocote $\AA$ na produção de mudas de tamarindeiro (Tamarindus indica). Ciência e Agrotecnologia, Lavras, v.32, n.2, p.391-397, 2008.

NATALE, W.; PRADO, R.M.; ALMEIDA, E.V.; BARBOSA, J.C. Adubação nitrogenada e potássica no estado nutricional de mudas de maracujazeiro-amarelo. Acta Scientiarum Agronomy, Maringá, v.28, n.2, p.187-192, 2006.

OLIVEIRA, R.P.; SCIVITTARO, W.B.; VASCONCELLOS, L.A.B.C. Avaliação de mudas de maracujazeiro em função do substrato e do tipo de bandeja. Scientia Agrícola, Piracicaba, v.50, n.2, p.261-266, 1993. Disponível em: <http//: www.scielo.com.br>. Acesso em: 15 fev. 2009.

PEZZOPANE, J.E.M.; OLIVEIRA, P.C. de; REIS, E.F. dos; LIMA, J.S. de S. Alterações microclimáticas causadas pelo uso de tela plástica. Engenharia Agrícola, Jaboticabal, v.24, n.1, p.915, 2004.

PINTO, J.E.B.P.; CARDOSO, J.C.W.; CASTRO, E.M.; BERTOLUCCI, S.K.; MELO, L.A.; DOUSSEAU, S. Aspectos morfofisiológicos e conteúdo de óleo essencial de plantas de alfazema-do-Brasil em função de níveis de sombreamento. Horticultura Brasileira, Brasília, v.25, n.2, p.210-214, 2007.

PIO, R.; GONTIJO, T.C.A.; RAMOS, J.D.; CARRIJO, E.P.; TOLEDO, M.; VISIOLI, E.L.; TOMASETTO, F. Produção de mudas de maracujazeiro-amarelo em diferentes substratos. Revista Brasileira de Agrociência, Pelotas, v.10, n.4, p.523-525, 2004.

PRADO, R.M.; VALE, D.W.; ROMUALDO, L.M. Fósforo na nutrição e produção de mudas de maracujazeiro. Acta Scientiarum Agronomy, Maringá, v.27, n.3, p.493-498, 2005.

QUINTINO, H. M. S. Benefícios sociais da política de incentivos à cultura do mamão no Estado do Ceará. Dissertação. 2007. 80 f. (Mestrado em Economia Rural) - Universidade Federal do Ceará, Fortaleza, 2007.

RIBEIRO, M.C.C.; MORAIS, M.J.A.; SOUSA, A.H.; LINHARES, P.C.F.; BARROS JÚNIOR, A.P. Produção de mudas de maracujá-amarelo com diferentes substratos e recipientes. Caatinga, Mossoró, v.18, n.3, p.155-158, 2005.

SENTELHAS, P.C.; VILLA NOVA, N.A.; ANGELOCCI, L.R. Efeito de diferentes tipos de cobertura, em miniestufas, na atenuação da radiação solar e da luminosidade. Revista Brasileira de Agrometeorologia, Santa Maria, v.6, n.1, p.479-481, 1998.

SILVA, R.P.; PEIXOTO, J.R.; JUNQUEIRA, N.T.V. Influência de diversos substratos no desenvolvimento de muda de maracujazeiro-azedo (Passiflora edulis Sims f. flavicarpa Deg). Revista Brasileira de Fruticultura, Jaboticabal, v.23, n.2, p.377-381, 2001.

SILVEIRA, A.P.D. da; SILVA, L.R. ; AZEVEDO, I.C.; OLIVEIRA, E.; MELETTI, L.M.M. Desempenho de fungos micorrízicos arbusculares na produção de mudas de maracujazeiro-amarelo, em diferentes substratos. Bragantia, Campinas, v.62, n.1, p.89-99, 2003.

SOUSA, G.B.; CAVALCANTE, L.F.; CAVALCANTE, I.H.L.; BECKMAN-CAVALCANTE, M.Z.; NASCIMENTO, J.A.M. Salinidade do substrato contendo biofertilizante para a formação de mudas de maracujazeiro irrigado com água salina. Caatinga, Mossoró, v.21, p.172-180, 2008.

VERDIAL, M.F.; LIMA, M.S. de; TESSARIOLI NETO, J.; DIAS, C.T. dos; BARBANO, M.T. Métodos de formação de mudas de maracujazeiro-amarelo. Scientia Agricola, Piracicaba, v.57, n.4, p.795-798, 2000.

WAGNER JÚNIOR, A.; ALEXANDRE, R.S.; NEGREIRO, J.R.; PIMENTEL, L.D.; COSTA E SILVA, J.O;; BRUCKNER, C.H. Influência do substrato na germinação e desenvolvimento inicial de plantas de maracujazeiro-amarelo (Passiflora edulis Sims f. flavicarpa Deg). Ciência e Agrotecnologia, Lavras, v.30, n.4, 2006. 
ZANELLA, F.; SONCELA, R.; LIMA, A.L.S. Formação de mudas de maracujazeiro-amarelo com níveis de sombreamento em Ji-Paraná - RO. Ciência e Agrotecnologia, Lavras, v.30, n.5, p.880$884,2006$. 